\title{
METHODICAL APPROACH FOR DETERMINATION OF THE HETEROCYCLIC AROMATIC AMINES IN MEAT PRODUCTS USING HPLC-MS/MS
}

Dmitry A. Utyanov ${ }^{1}{ }^{*}$ Andrey V. Kulikovskii ${ }^{1}$, Aleksandra S. Knyazeva ${ }^{1}$, Anastasiya A. Kurzova ${ }^{1}$, Andrey N. Ivankin ${ }^{2}$ ${ }^{1}$ V.M. Gorbatov Federal Research Center for Food Systems of Russian Academy of Sciences, Moscow, Russia ${ }^{2}$ Mytischi Branch (MB) of Bauman Moscow State Technical University (National Research University), Mytischi, Moscow region, Russia

Keywords: food safety, carcinogens, PhIP, MeIQx, chromatography

\begin{abstract}
Heterocyclic aromatic amines (HAA) are formed in foods of animal origin during the Maillard reaction due to the high creatine and creatinine contents. HAA have carcinogenic and mutagenic effects. HAA content is not standardized in the Russian Federation and the Customs Union territory. However, in the EU countries, comprehensive monitoring studies are carried out on the HAA contents and effect on the human body. Due to constant expansion of the list of controlled contaminants in food products, analytical laboratories need to develop methods for determining HAA in food items. As a result of the research, a method for HAA determination was developed using high-performance liquid chromatography with mass spectrometry in the mode of specified reaction monitoring. Comparative tests of the two methods for sample preparation were carried out. The advantages and disadvantages of sample preparation approaches were substantiated. The existing SPE conditions were optimized, which made it possible to concentrate trace amounts of MeIQx and PhIP and to dispose of substances suppressing analyte ionization. The estimation of method accuracy and specificity was carried out. The degree of ionization suppression by the matrix for MeIQx and PhIP analytes was determined. The degree of HAA extraction was empirically established. For biological samples of animal origin, it was up to 90.9\% for MeIQx and up to $89.4 \%$ for PhIP. It is shown that, in accordance with the developed methodology, HAA may be determined with an accuracy of 96.15 to $98.4 \%$ at the levels of 5 to $20 \mathrm{ng} / \mathrm{g}$. The limit of quantification of the target substances was $3 \mathrm{ng} / \mathrm{g}$.
\end{abstract}

\section{Funding:}

The research was supported by state assignment of V. M. Gorbatov Federal Research Centre for Food Systems of RAS, scientific research No. FNEN-2019-0007.

\section{Introduction}

Heat treatment of food products leads to the formation and/or accumulation of new compounds. Often, such compounds are not useful and, moreover, may also harm human health due to their mutagenic and carcinogenic properties. These compounds include heterocyclic aromatic amines (HAA), which are formed in foods as a result of high-temperature treatment. Heterocyclic aromatic amines are a group of compounds with at least one aromatic ring and one amino group in their structure. HAA are formed mainly during high-temperature treatment (for example, frying, grilling, etc.) of animal products due to their relatively high contents of creatine/ creatinine, which are the basis for HAAs [1]. According to [2], the HAA formation reaction proceeds by cleavage of water from creatine and its further cyclization to creatinine, which forms the amino-imidazole part of the HAA molecule being its basis. Then pyrazines and pyridines formed from unbound amino acids and hexoses during the Maillard reaction complete the HAA molecule formation. The effect of unbound amino acids on the formation of amino-imidazoarene HAAs was studied by Meurillon, M. et al. [3]. An important participant in the
HAA molecule formation is the Strecker aldehyde or the corresponding Schiff base (Figure 1).

A number of studies carried out on laboratory animals and protozoans have found that HAA have carcinogenic and mutagenic effects. Using the Ames test in studies on Salmonella, it was found that HAA have the highest mutagenic and carcinogenic activity compared to other mutagens and carcinogens consumed by humans with food. However, with a normal diet, a person consumes "insufficient" amount of HAA with food for the formation of malignant tumors. In addition, the consumption of HAA with other types of carcinogens and mutagens leads to additional synergistic effects due to their ability to cause gene instability and increase sensitivity to tumor promoters [4]. HAA genotoxicity was proven by the authors in [5]. The carcinogenic potential of HAA may be enhanced in the presence of tumor promoters and agents that enhance cell proliferation. This was published in [6]: according to the results, skin tumors on the back of mice coated with TrpP-2 HAA began to develop only after the subsequent application of TPA (12-O-tetradecanoylphorbol-13-acetate), a promoter of skin carcinogenesis. HAA may form new mutagenic compounds or enhance existing mutagenic pro- 


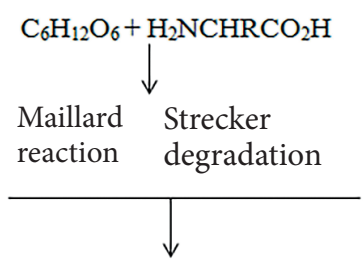<smiles>CN(CC(=O)O)C(=N)N</smiles><smiles>CN(CC(=O)O)C(=N)NP(=O)(O)O</smiles><smiles></smiles><smiles>CN1CC(=O)NC1=N</smiles><smiles>CN1CC(=O)N=C1N</smiles><smiles>Cn1cc(O)nc1N</smiles>

$\mathrm{Q}=\mathrm{CH}, \mathrm{N}$ Creatinine

\begin{tabular}{|l|l|l|l|l|}
\hline Abbreviation & X & A & Q & R \\
\hline IQ & $\mathrm{H}$ & $\mathrm{H}$ & $\mathrm{CH}$ & $\mathrm{H}$ \\
\hline MeIQ & $\mathrm{H}$ & $\mathrm{H}$ & $\mathrm{CH}$ & $\mathrm{Me}$ \\
\hline MqIQx & $\mathrm{H}$ & $\mathrm{Me}$ & $\mathrm{N}$ & $\mathrm{H}$ \\
\hline 7,8-DiMeIQx & $\mathrm{Me}$ & $\mathrm{Me}$ & $\mathrm{N}$ & $\mathrm{H}$ \\
\hline 4,8-DiMeIQx & $\mathrm{H}$ & $\mathrm{Me}$ & $\mathrm{N}$ & $\mathrm{Me}$ \\
\hline
\end{tabular}

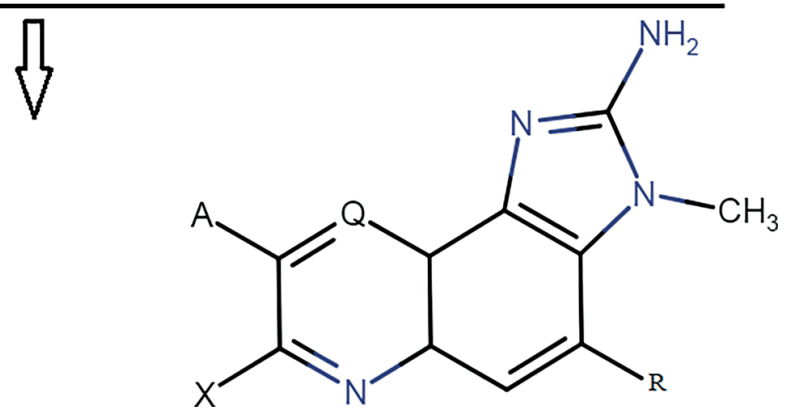

Figure 1. HAA formation mechanism

perties. For example, non-mutagenic aniline and norharman form aminophenyl norharman, which, upon further activation with a mixture of $S 9$ enzymes to hydroxyaminophenyl norharman and its final transformation into acetoxy derivatives, leads to the formation of DNA adducts (Figure 2) causing mutations. In experiments on rodents, the formation of aminophenyl norharman from aniline and norharman was established in vivo; and it also had carcinogenic properties along with mutagenic ones [7]. The works [8-10] show that consumption of products with high HAA contents may cause colorectal cancer.
The carcinogenic and mutagenic effect of HAA shown in [5-10] requires minimization of the HAA amount in meat products and conducting the corresponding studies. As noted above, the temperature and duration of heat treatment play an important role in the reaction of HAA formation. An increase in temperature and duration proportionally increases the amount of HAA [11], therefore, the most effective way to reduce them is to influence precisely these parameters. But this will have a strong effect on product sensory properties. In this regard, a large number of studies on the ways to reduce the HAA amount are based<smiles></smiles><smiles>Nc1ccc(-n2c3ccccc3c3ccncc32)cc1</smiles>

9-(4'-Aminophenyl)-9H-pyrido [3,4-b] indole<smiles>ONc1ccc(-n2c3ccccc3c3ccncc32)cc1</smiles>
(aminophenyl norharman, APNH)

N-hydroxy APNH
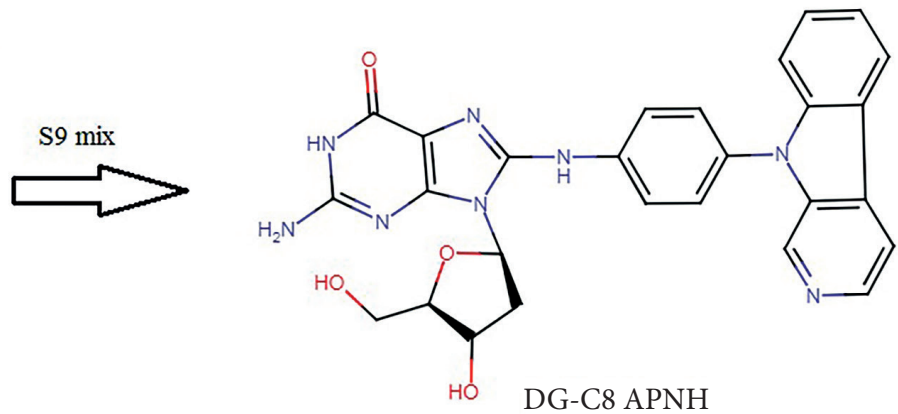

Figure 2. The reaction of aminophenyl norharman formation with the subsequent formation of DNA adducts from it 
on changes in product formulations, in particular, introduction of the components that have an inhibitory effect in the HAA formation reaction. Sugars are inhibitors in the HAA formation reaction. During the Maillard reaction, 5-hydroxymethyl-2-furfural is formed from sugars, which simultaneously reduces the amount of HAA formed, as it reacts with creatin/creatinine [12]. Honey, a rich source of glucose and fructose, is the most effective among low molecular weight carbohydrate sources in reducing the amount of HAA formed [13]. Antioxidants have a strong inhibitory effect on the HAA formation reaction [14]. The effect of introducing rosemary and grape seed extracts into a meat product was investigated. The greatest reduction in the MeIQx and PhIP amounts was achieved when $0.8 \%$ grape seed extract in the form of a water-in-oil emulsion and $1.5 \%$ solution of rosemary extract in sunflower oil were added to the formulation. The effect of adding pomegranate seed extract was also investigated [15]. According to the results, most of the samples showed an increase in HAAs, but it is worth noting that there were many more factors in this work that may affect the amount of HAA, since the product contained many more components in addition to meat and a potential inhibitor. The results of a study on the hawthorn extract inhibitory potential in the reaction of HAA formation were published [16]. These results were rather contradictory, as both an increase and a decrease in HAAs formed were observed in the test samples. In [17], the inhibitory effect of artichoke extract was investigated. According to the results, artichoke extract has a strong inhibitory effect on the HAA formation reaction.

The role of fat in the HAA formation reaction should be noted. Less fat in the raw material results in more HAA formed [18]. This may be due to the fact that fat, being a good heat carrier, leads to faster cooking, which reduces the HAA contents in the finished product. In addition, replacing animal fat with vegetable oils may reduce the amount of HAAs formed by up to $100 \%$. Gunter, F. et al. [19] studied the effect of replacing animal fat with vegetable oils. They made patties from lean pork with the addition of pork fat ( $60 \%$ of the total fat content), sunflower oil, olive oil or pomegranate oil ( $40 \%$ of the total fat content). The results showed that replacing $40 \%$ of animal fat in a meat product with vegetable oil led to a significant decrease in the amount of HAAs formed during heat treatment. The decrease in total HAA content in the products ranged from $83 \%$ to $100 \%$ (the largest decrease was found when adding pomegranate oil) [19]. Like various vegetable oils, the type of animal fat also affects the amount of HAAs. The addition of broadtail fat to the meat product leads to more HAA formation than the addition of beef fat [20].

But prior to studies on reducing the amount of HAAs, it is necessary to develop a methodology for their determination. The development of methodological approaches includes two main stages: sample preparation and setting the conditions for chromatographic analysis. Currently, the majority of HAA quantification studies are based on solid phase extraction (SPE) of the analytes to be determined followed by analysis on an HPLC-MS/MS system. The SPE method of sample preparation was proposed in 1992 and is based on alkaline hydrolysis of the sample followed by extraction of analytes using Oasis MCX SPE cartridges. The HPLC-MS/MS method is preferred because of its high selectivity, which makes it most suitable for the quantitative determination of HAAs. But it is worth noting that HAAs can also be determined by other chromatographic methods, such as detection in the ultraviolet spectrum or the use of an ion trap (Orbitrap) [21,22]. This certainly makes the analysis even more accurate, but the ion trap technology combined with mass spectrometry is relatively new and the equipment required is not so widespread as the HPLCMS/MS systems. It is important to note that there are other ways to prepare samples. For example, the method of magnetic SPE with iron oxide (II, III) nanoparticles [23]. HAA extraction is possible using QuEChERS cartridges, but they have been tested only on baked foods and may not work with meat matrices [24].

Based on the above, the purpose of this work was to substantiate the conditions for the chromatographic determination of HAA in meat products using HPLC-MS/MS and to compare the slightly modified method of sample preparation with solid-phase extraction (SPE) used in foreign laboratories and the method of sample preparation with liquid extraction by an organic solvent developed by the authors of the work.

\section{Materials and methods}

Among more than 30 currently known heterocyclic aromatic amines formed in meat products during heat treatment, 2-amino-3,8-dimethylimidazo[4,5-f] quinoxaline (MeIQx) and 2-amino-1-methyl-6-phenylimidazo[4,5-b] pyridine (PhIP) were selected, since they account for $80-$ $90 \%$ of the total amount of HAAs. Thus, they may be considered markers of HAA presence in meat products. In this connection, when setting up the method for determining HAAs in meat products, we used:

- standard sample of 2-amino-3,8-dimethylimidazo[4,5f] quinoxaline (MeIQx) manufactured by Toronto Research Chemicals (Canada) with a basic substance content of at least $99.0 \%$;

- standard sample of 2-amino-1-methyl-6-phenylimidazo[4,5-b] pyridine (PhIP) manufactured by ChemCruz (USA) with a basic substance content of at least $95.0 \%$. When selecting the conditions for chromatographic identification, the following reagents were used: acetonitrile for HPLC manufactured by Panreac (France), formic acid by Merck (USA), deionized water obtained on MilliQDirect 8 system (France).

Standard samples were dissolved in methanol with subsequent dilution to achieve concentrations of 1000, 100, 10, and $1 \mathrm{ng} / \mathrm{cm}^{3}$. 
The analysis was performed on Agilent 1200 high performance liquid chromatography system (USA) with Agilent $6410 \mathrm{~B}$ three-quadrupole mass spectrometer.

To determine HAA, C18 chromatographic column, $4.6 \times 50 \mathrm{~mm}, 1.8 \mu \mathrm{m}$ (Agilent, USA) was used.

\section{Results and discussion}

Chromatographic separation of the analytes to be determined was carried out in the gradient elution mode (two-component mobile phase);

injected sample volume is $0.01 \mathrm{~cm}^{3}$;

mobile phase flow rate is $0.4 \mathrm{~cm}^{3} / \mathrm{min}$;

column thermostat temperature is $35^{\circ} \mathrm{C}$.

Despite the fact that aromatic compounds are not fragmented, due to the presence of a methyl radical in the substances selected in the work, their fragmentation is possible under certain conditions with the formation of a daughter ion. This makes it possible to use MRM technology in the determination of HAAs. So, the possibility of false positive or false negative identification of the analytes is minimized. The developed conditions for the detection of analytical signals in the MRM mode are presented in Table 1.

Table 1. Ion exposure parameters in MRM mode and electric spray ionization (ESI) conditions with positive $(+)$ and negative $(-)$ ion registration

\begin{tabular}{|c|c|c|c|c|} 
Analyte & $\begin{array}{c}\text { Molecular } \\
\text { ion, m/z }\end{array}$ & $\begin{array}{c}\text { Daughter } \\
\text { ions, m/z }\end{array}$ & $\begin{array}{c}\text { Fragmentor } \\
\text { voltage (Frag), V }\end{array}$ & $\begin{array}{c}\text { Cleavage } \\
\text { energy (CE), V }\end{array}$ \\
\hline MeIQx & $214.6(+)$ & 199.5 & 130 & 30 \\
\hline PhIP & $225.6(+)$ & 210.5 & 130 & 30 \\
\hline
\end{tabular}

For the chromatographic separation of substances, the two-component mobile phase was used:

- eluent $\mathrm{A}$ is $0.1 \%$ formic acid solution in acetonitrile;

- eluent B is $0.1 \%$ formic acid solution in deionized water. Gradient elution conditions are shown in Table 2.

Table 2. Gradient elution conditions

\begin{tabular}{|c|c|c|c|}
\hline Time, $\min$ & A, \% об. & B, \% об. & Flow rate, $\mu \mathrm{L} / \mathrm{min}$ \\
\hline $\mathbf{0}$ & 10 & 90 & 400 \\
\hline 4 & 40 & 60 & 400 \\
\hline 6 & 60 & 40 & 400 \\
\hline 8 & 90 & 10 & 400 \\
\hline 8.1 & 90 & 10 & 400 \\
\hline 12 & 10 & 90 & 400 \\
\hline
\end{tabular}

The selected conditions and the analyte release time shown in Figure 3 (illustrating the chromatogram of the total ion current superposition (red) on the MRM of the PhIP daughter ions (green, release time $\approx 5.9 \mathrm{~min}$ ) and the MeIQx daughter ions (blue, release time $\approx 4.5 \mathrm{~min}$ )) indicate that the MeIQx substance is washed out from the chromatographic column at the A: B eluent ratio of $60: 40 \%$, and the PhIP substance is washed out from the chromatographic column at the A: B eluent ratio of 90:10\%.

The described chromatography conditions made it possible to detect HAAs in concentrations as low as $1 \mathrm{ng} / \mathrm{cm}^{3}$, which is the optimal lower limit of detection for HAAs in meat products. Figure 4 shows chromatograms of HAA standard mixture at a level of $1 \mathrm{ng} / \mathrm{mL}$ with chromatograms of their daughter ions.

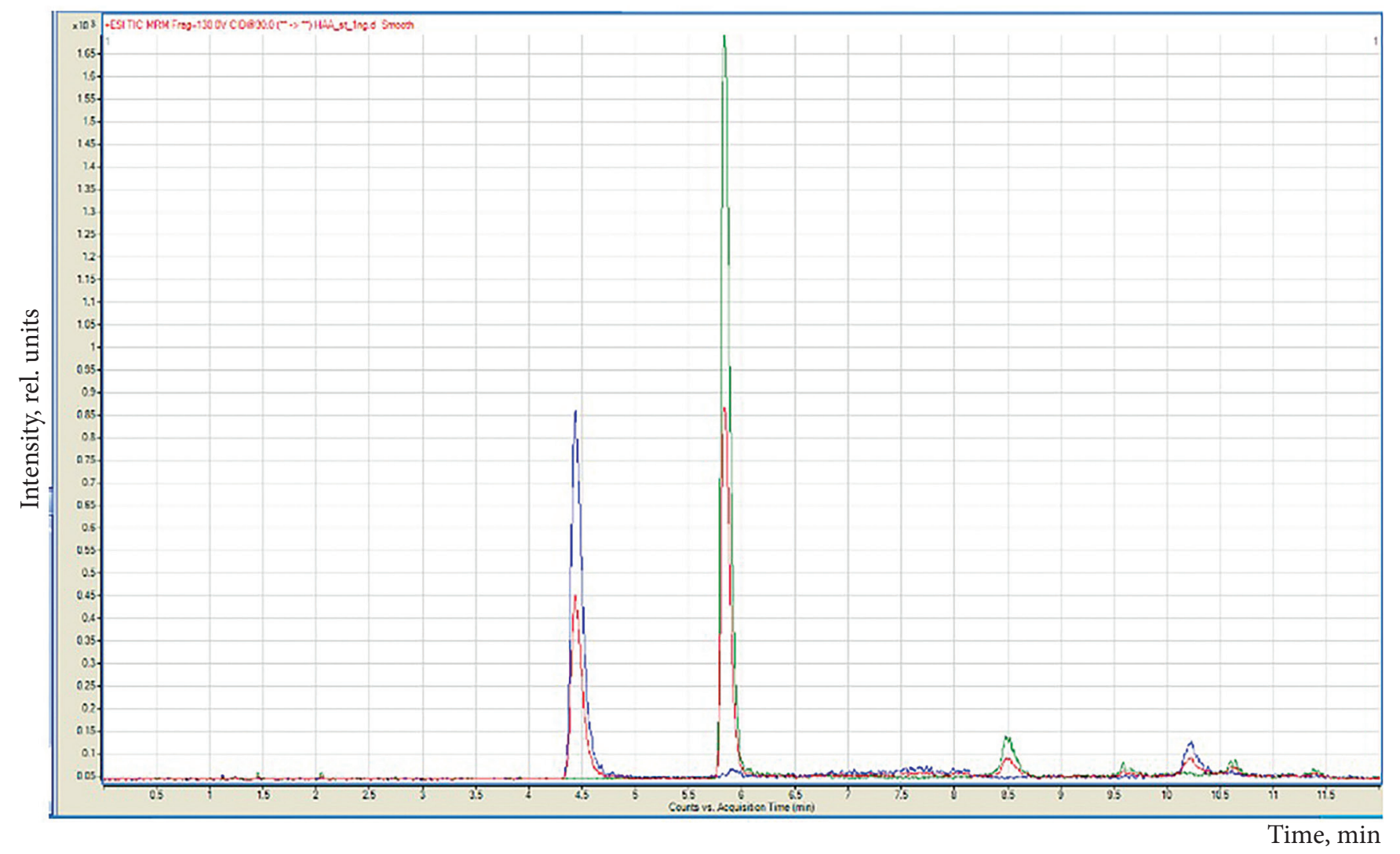

Figure 3. Chromatogram of the total ion current superposition on the PhIP daughter ions and the MeIQx daughter ions 


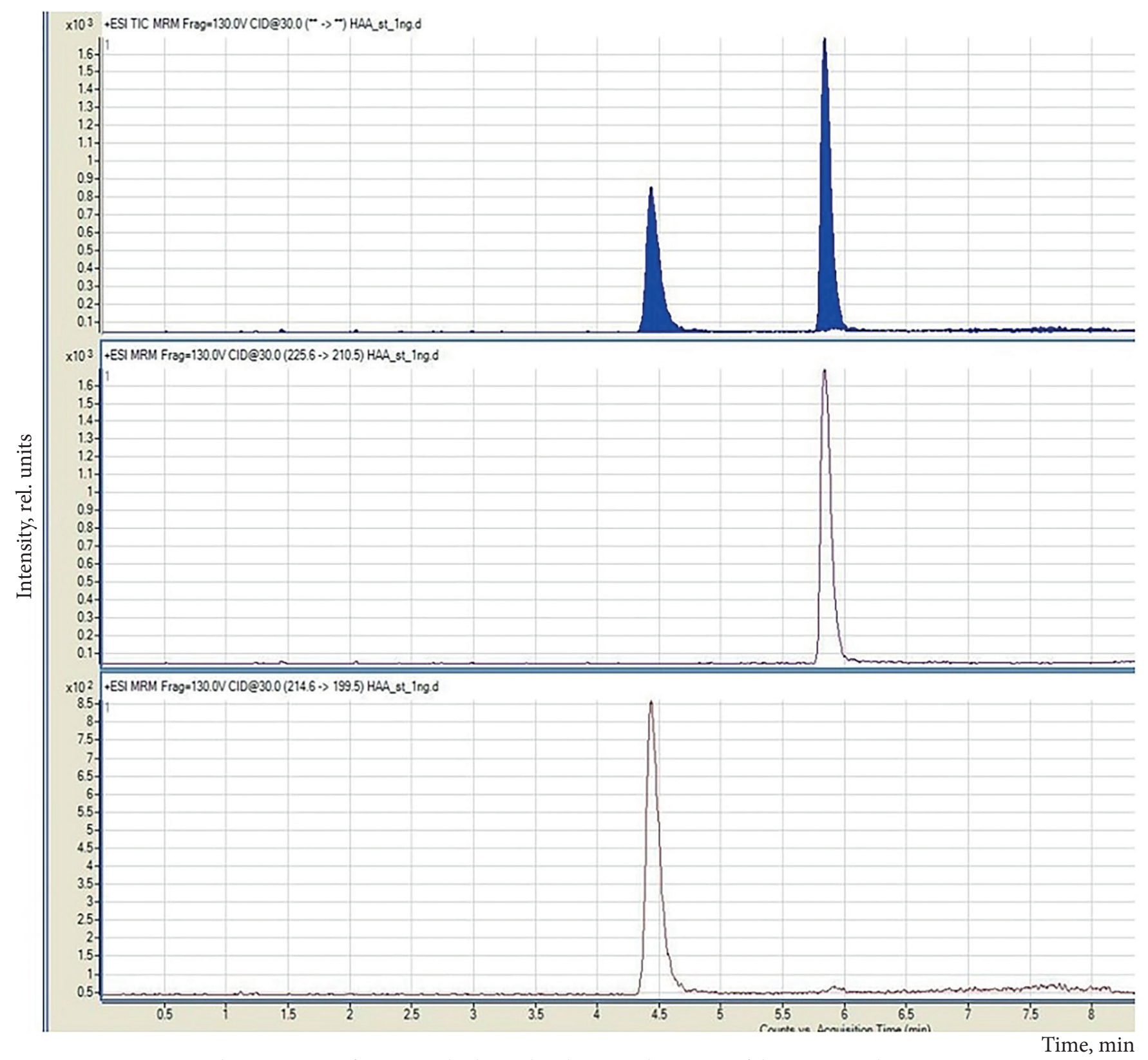

Figure 4. Chromatogram of HAA standard sample solution. Release time of the MeIQx analyte is 4.5 minutes; release time of the PhIP analyte is 6 minutes

\section{Sample preparation}

In foreign practice, preparation of meat product samples to determine the HAA content in it is carried out by the alkaline hydrolysis with SPE, for example $[25,26]$. In our studies, this method was optimized taking into account the available equipment and reagents. The method for determining HAAs include preliminary alkaline hydrolysis of the sample followed by the solid-phase extraction (SPE) and identification using HPLC-MS/MS.

A sample of the analyzed product $(3.00 \pm 0.01 \mathrm{~g})$ was placed in a $250 \mathrm{~cm}^{3}$ round-bottom flask with a sleeve. Then $50 \mathrm{~cm}^{3}$ of $1 \mathrm{M}$ sodium hydroxide solution in ethanol was added. The flask was connected to a reflux condenser, placed in a water bath and heated at a temperature of $80 \pm 2{ }^{\circ} \mathrm{C}$ for 30 minutes or until the sample was completely dissolved. The flask contents were periodically stirred with a borosilicate glass rod. After that, the flask contents were cooled by adding $30-50 \mathrm{~cm}^{3}$ of distilled water. Cooling with water is necessary to prevent solidification of the hydrolysate, which may complicate further sample preparation. The hydrolysate was mixed with $6 \mathrm{~g}$ of diatomite and transferred to a 500 $\mathrm{cm}^{3}$ separatory funnel. Hydrolysate transfer to the separatory funnel must be carried out carefully to minimize the amount of diatomite in the funnel, as it may complicate handling the separatory funnel. $10 \mathrm{~cm}^{3}$ of ethyl acetate was added to the hydrolysate, mixed thoroughly and allowed to settle. After separation, the lower layer was transferred to a second separatory funnel for re-extraction with $10 \mathrm{~cm}^{3}$ of ethyl acetate. The upper ethyl acetate layer obtained after the first and second extractions was pooled into a $50 \mathrm{~cm}^{3}$ centrifuge tube. After that, the sample was centrifuged for 10 minutes with an acceleration of $5000 \mathrm{~g}$ for complete separation. The supernatant obtained after centrifugation was used for SPE.

For SPE extraction, Oasis MCX 6cc (150 mg) LP Extraction Cartridges (manufactured by Waters, Ireland) were used. The SPE cartridges were pre-activated by passing 
$6 \mathrm{~cm}^{3}$ of methanol, and then $6 \mathrm{~cm}^{3}$ of $0.1 \mathrm{M}$ hydrochloric acid in deionized water. The solution to be analyzed was applied to the cartridge at a rate of $1 \mathrm{~cm}^{3} / \mathrm{min}$, while collecting the ethyl acetate extract. The cartridge was washed by passing $6 \mathrm{~cm} 3$ of $0.1 \mathrm{M}$ hydrochloric acid in deionized water and $6 \mathrm{~cm}^{3}$ of methanol, while discarding the washings. Analytes were eluted with $6 \mathrm{~cm}^{3}$ of methanol-ammonia mixture in a ratio of 19:1 at a rate of $1 \mathrm{~cm}^{3} / \mathrm{min}$ and transferred to a round-bottom flask, while pooling with an ethyl acetate extract. The solution was evaporated to obtain a dry residue on a rotary evaporator at a temperature not exceeding $40^{\circ} \mathrm{C}$. Then, $1 \mathrm{~cm}^{3}$ of methanol was added to the dry residue, transferred for 5 minutes into an ultrasonic bath until the residue was completely dissolved. The solution was passed through a membrane filter with a pore diameter of $0.45 \mu \mathrm{m}$ into a $2 \mathrm{~cm}^{3}$ chromatographic vial for HPLC-MS/MS analysis.

The degree of extraction in this sample preparation technique was determined by the "added/found" method. For this purpose, solutions of standard samples were added to the sample initially free of HAAs to obtain approximate values of $10 \mathrm{ng} / \mathrm{g}$. Sterilized canned beef was used as a HAA-free sample, as the temperature of their heat treatment is closest to the temperatures at which HAAs are formed, but insufficient for their formation.

According to the results, the samples contained 9.09 ng/g MeIQx and $8.94 \mathrm{ng} / \mathrm{g}$ PhIP. Thus, the extraction degree was $\approx 90.9 \%$ and $\approx 89.4 \%$ for MeIQx and PhIP, respectively.

Further, the stability of the extraction was determined. For this, solutions of HAA standard samples were added to the sample initially free of HAA. Sterilized canned beef was also used as a HAA-free sample. Nine samples were prepared: 3 samples with the addition of HAA standard solutions to achieve the concentration of $10 \mathrm{ng} / \mathrm{g} ; 3$ samples to achieve the concentration of $25 \mathrm{ng} / \mathrm{g}$; and 3 samples to achieve the concentration of $50 \mathrm{ng} / \mathrm{g}$. The extraction degree for all samples was about $90 \%$.

Despite the fact that the described method allows the extraction of HAAs from meat products with a high and stable degree of extraction, it may be not convenient in laboratory practice, because the SPE process significantly increases the analysis time.

To solve this problem, other methods of sample preparation were tested, i. e. salting out with elution with acetonitrile, salting out with elution with methanol, acid hydrolysis, alkaline hydrolysis, followed by liquid extraction with hexane. However, the use of the above approaches led to an extremely low degree of extraction and insufficient purification from extraneous organic compounds. Optimal results were obtained using alkaline hydrolysis of the sample followed by extraction of HAAs from the hydrolysate with an organic solvent, diethyl ether.

A sample of the analyzed product $(3.00 \pm 0.01 \mathrm{~g})$ was placed in a $250 \mathrm{~cm}^{3}$ round-bottom flask with a sleeve. Then $50 \mathrm{~cm}^{3}$ of $1 \mathrm{M}$ sodium hydroxide solution in ethanol was added. The flask was connected to a reflux condenser, placed in a water bath and heated at a temperature of $80 \pm$ $2{ }^{\circ} \mathrm{C}$ for 30 minutes or until the sample was completely dissolved. The flask contents were periodically stirred with a borosilicate glass rod. After that, the flask contents were cooled by adding the distilled water. The resulting hydrolysate was transferred into a separatory funnel with a volume of at least $250 \mathrm{~cm}^{3}$. Then $25 \mathrm{~cm}^{3}$ of diethyl ether was added to the separatory funnel and allowed to settle for 1-5 minutes for separation of layers. Then the bottom layer was transferred into another separatory funnel with a volume of at least $250 \mathrm{~cm}^{3}$ for re-extraction. Then $25 \mathrm{~cm}^{3}$ of diethyl ether was added to it and for separation of layers. After that, the lower layer was poured off, and the ether layer obtained after the first extraction was added to the upper ether layer. The resulting ether was washed 3 times with 25 to $30 \mathrm{~cm}^{3}$ portions of distilled water for sample purification from alkali. Then the ether layer was passed through a membrane filter with 15 to $20 \mathrm{~g}$ of sodium sulfate for dehydration. The resulting ether was evaporated to dry residue at a temperature not exceeding $40{ }^{\circ} \mathrm{C} .1 \mathrm{~cm}^{3}$ of methanol was added to the dry residue and transferred to an ultrasonic bath until the residue was completely dissolved. The solution was passed through a membrane filter with a pore diameter of $0.45 \mu \mathrm{m}$ into $2 \mathrm{~cm}^{3}$ chromatographic vial for HPLC-MS/MS analysis.

Similarly to sample preparation with SPE, the degree of extraction was determined by the "added/found" method. The results showed that the extraction degree for the analytes to be determined was $\approx 78.3 \%$ for MeIQx and $\approx 82.0 \%$ for PhIP, which is a satisfactory.

When using this sample preparation method, it is necessary to take into account the possibility of incomplete separation of organic solvents in liquid-liquid extraction. In this case, a mixture of ethanol and water enters into the ether layer leading to the sample contamination. Also, after the evaporation of the ether layer, a mixture of ethanol and water may remain in the flask, which must be further evaporated at higher temperatures.

Tables 3 and 4 show the amounts of reagents for sample preparation by SPE and liquid-liquid extraction, respectively.

Table 3. Calculating the amounts of chemical reagents in the HAA analysis with sample preparation by the SPE

Reagent name

Reagent amounts per 1 analysis

Sodium hydroxide

$4 \mathrm{~g}$

Ethanol

$100 \mathrm{ml}$

Diatomite

$12 \mathrm{~g}$

\begin{tabular}{l|r|} 
Ethyl acetate & $40 \mathrm{ml}$
\end{tabular}

Methanol

$38 \mathrm{ml}$

Hydrochloric acid

0.44

Ammonia

0.6

SPE cartridge

2 
Table 4. Calculating the amounts of chemical reagents in the HAA analysis with sample preparation by the liquid-liquid extraction

Reagent name

Sodium hydroxide

Ethanol

Diethyl ether

Sodium sulfate dehydrated

Methanol

Reagent amounts per 1 analysis

$4 \mathrm{~g}$

$100 \mathrm{ml}$

$100 \mathrm{ml}$

$50 \mathrm{~g}$

$2 \mathrm{ml}$

The elimination of the SPE process reduces the analysis time and significantly reduces the cost of the sample preparation. The SPE advantage is the reduction in total solvent amount during sample preparation, which has a positive effect on the method safety. In HAA determination, SPE elimination does not reduce the accuracy and reliability of the results.

The use of chromatography with mass spectrometry detection for qualitative HAA analysis is associated with the so-called "matrix effects". To confirm the absence of cross interferences in the mass spectrometry at the collision chamber of the quadrupole analyzer, "matrix effects" were investigated by analyzing the target substances in blank samples and deionized water. The ratio of the blank sample peak area to water was calculated. The studies have shown that the biological matrix suppressed signal for the analytes determined, which decreased the accuracy and reliability of the method. The degree of signal suppression by the matrix was $\approx 22 \%$ for MeIQx and $\approx 19 \%$ for PhIP. To take into account the matrix effect, a matrix calibration was carried out.

To do this, a solution of standard samples was added to previously analyzed samples not containing analytes until concentrations of $6,10,15,30,60,100,150,300,600 \mathrm{ng} / \mathrm{ml}$ and $5.5,9.1,13.75,27.5,55,91,137.5,275,550 \mathrm{ng} / \mathrm{ml}$ were reached for MeIQx and PhIP, respectively. These concentrations were selected on the basis of the analyzed literature on the amounts of HAAs formed in meat products.
When preparing solutions for calibration, $200 \mu \mathrm{L}$ of solutions with established concentrations were added to $800 \mu \mathrm{L}$ of a HAA-free sample to achieve concentrations of $6,10,15,30,60,100,150,300,600 \mathrm{ng} / \mathrm{ml}$ and 5.5, 9.1, 13.75, 27.5, 55, 91, 137.5, 275, $550 \mathrm{ng} / \mathrm{ml}$ for MeIQx and PhIP, respectively. The chromatographic analysis of the obtained solutions showed a strong decrease in the signal suppression due to the matrix effect, and the results allowed linear matrix calibration. The linear regression correlation coefficient $\mathrm{R}$ was not less than 0.99 . The linear regression equation of the linear calibration for MeIQx is as follows:

$$
y=6048.379788^{*} x-60190.588646
$$

The linear regression equation of the linear calibration for PhIP is as follows:

$$
y=14433.213689^{\star} x+21370.000524
$$

where $y$ is the analyte concentration, $x$ is the peak area.

Calibration plots for MeIQx and PhIP are shown in Figure 5 and Figure 6, respectively.

The range of values established in the calibration is optimal for HAA studies, since the ranges of the detectable concentrations are 5.5 to $550 \mathrm{ng} / \mathrm{ml}$ and 6.0 to $600 \mathrm{ng} / \mathrm{ml}$ on average for MeIQx and PhIP, respectively.

Based on the results, the limit of detection and the limit of quantification were determined. The method with the sample preparation technique for liquid extraction was validated and the indicators of accuracy and specificity were established. The method was validated in accordance with EU Commission Directive 2002/6571. To perform validation, the results were obtained and processed according to the following parameters: specificity; linearity; correctness (degree of extraction); limit of detection (LOD), limit of quantification (LOQ). To confirm method specificity, 10 samples of meat products not containing MeIQx and

${ }^{1}$ Commission Decision 2002/657/EC implementing Council Directive 96/23/EC concerning the performance of analytical methods and the interpretation of results.

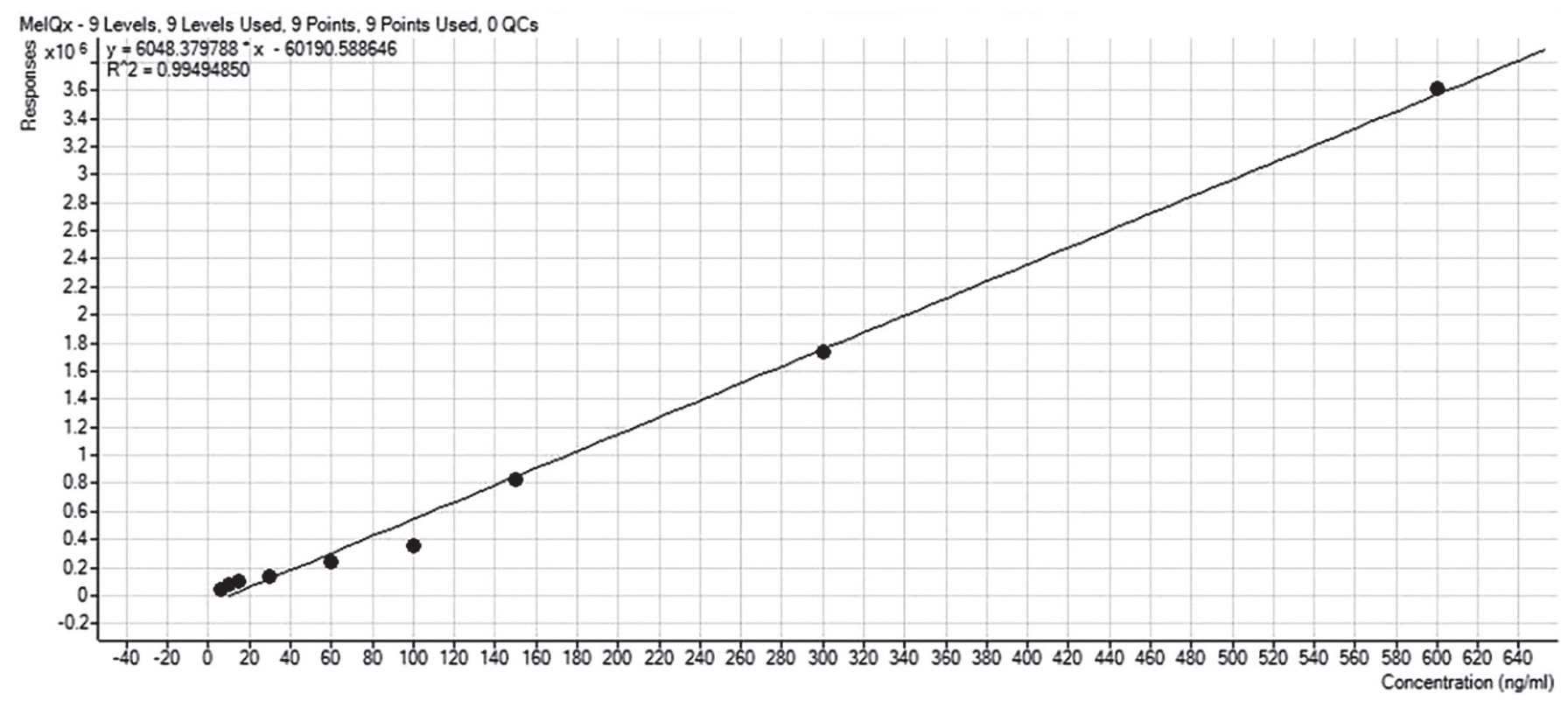

Figure 5. Linear calibration plot for MeIQx 


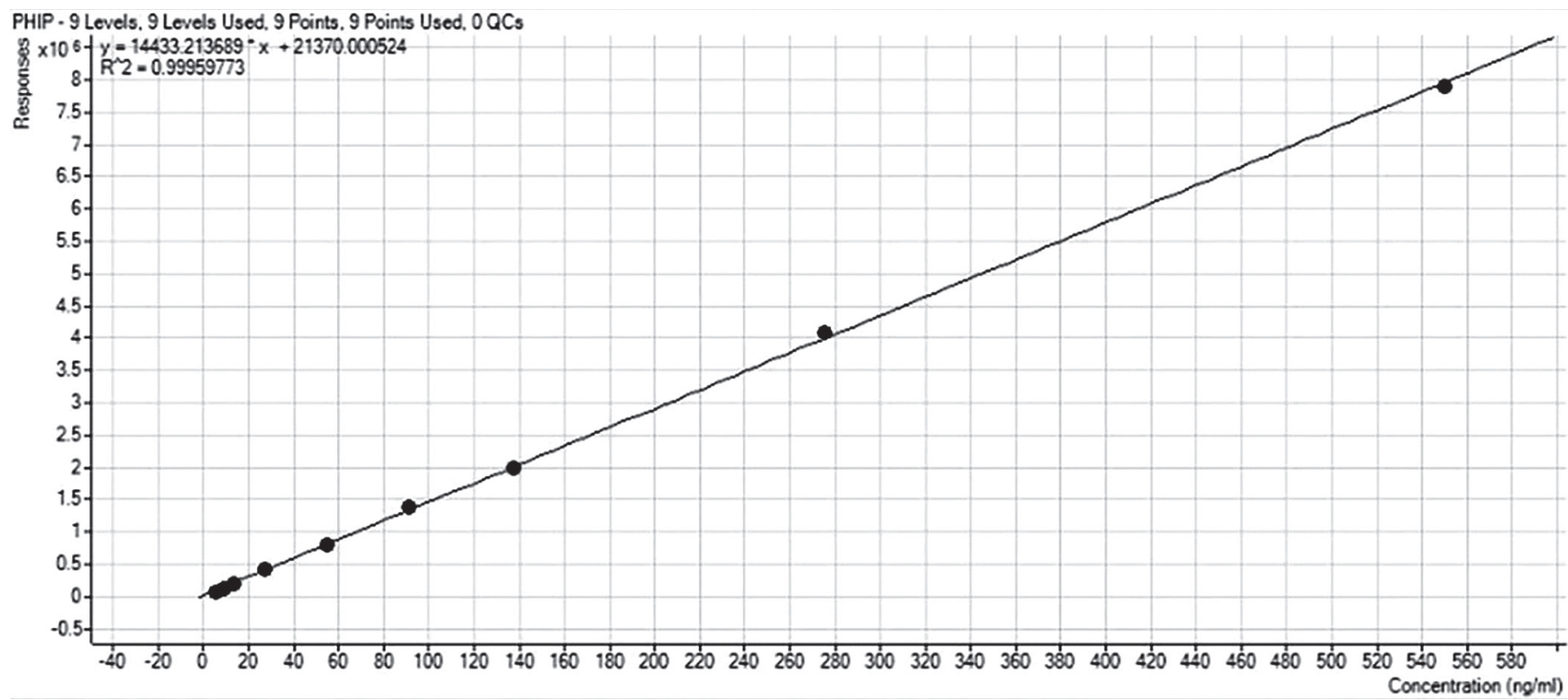

Figure 6. Linear calibration plot for PhIP

PhIP were examined. All 10 samples did not have chromatographic peaks interfering with the determination of MeIQx and PhIP. The technique allows for reliable determination of MeIQx and PhIP in the presence of impurities and systemic peaks of the mobile phase. The linear correlation coefficient of the obtained calibration curves was no less than 0.99 in the concentration range of 5.5 to 550 $\mathrm{ng} / \mathrm{ml}$ and 6.0 to $600 \mathrm{ng} / \mathrm{ml}$ for MeIQx and PhIP, respectively. LOD and LOQ were defined as the signal-to-noise ratio $(\mathrm{S} / \mathrm{N})$ for daughter ions of at least 1:3 for LOD and at least 1:10 for LOQ. The measurement results were obtained using 12 samples of a meat product with added MeIQx and $\mathrm{PhIP}$ at the concentration of $0.1 \mathrm{ng} / \mathrm{ml}, 0.5 \mathrm{ng} / \mathrm{ml}, 1.0 \mathrm{ng} / \mathrm{ml}$, $2.0 \mathrm{ng} / \mathrm{ml}, 3.0 \mathrm{ng} / \mathrm{ml}, 4.0 \mathrm{ng} / \mathrm{ml}, 5.0 \mathrm{ng} / \mathrm{ml}, 6.0 \mathrm{ng} / \mathrm{ml}, 7.0$ $\mathrm{ng} / \mathrm{ml}, 8.0 \mathrm{ng} / \mathrm{ml}, 9.0 \mathrm{ng} / \mathrm{ml}, 10.0 \mathrm{ng} / \mathrm{ml}$. The limit of detection (LOD) for MeIQx and PhIP was $0.5 \mathrm{ng} / \mathrm{g}$. The limit of quantification (LOQ) for MeIQx and PhIP was $3 \mathrm{ng} / \mathrm{g}$.

Accuracy was assessed by nine repeated measurements of standards at the concentration of 5.0, 10.0, and 20.0 $\mathrm{ng} / \mathrm{ml}$. Intralaboratory reproducibility was calculated from the results of the analysis with a solution obtained by another chemist in the laboratory using the same equipment. The relative standard deviation of the peak area did not exceed $5 \%$. The analyte determination accuracy varied in the range of 95 to $98 \%$. Accuracy parameters are shown in Table 5.

The method specificity was confirmed by the absence of analyte peaks in the analysis of 10 pure samples after analyzing the sample containing the highest calibration concentration $(550 \mathrm{ng} / \mathrm{ml}$ and $600 \mathrm{ng} / \mathrm{ml}$ for MeIQx and PhIP, respectively). No HAA peaks were observed during the analysis of blank samples.
Table 5. Accuracy and reliability of the developed method for determining HAAs in meat products

\begin{tabular}{|c|c|c|c|}
\hline Analyte & $\begin{array}{c}\text { Concentration, } \\
\text { ng/ml }\end{array}$ & $\begin{array}{c}\text { Relative standard } \\
\text { deviation, \% }\end{array}$ & Accuracy, \% \\
\hline \multirow{3}{*}{ MeIQx } & 5.0 & 5.40 & 96.15 \\
\hline \multirow{3}{*}{ PhIP } & 10.0 & 2.47 & 97.08 \\
\hline & 20.0 & 1.93 & 96.54 \\
\hline & 5.0 & 3.59 & 97.18 \\
\hline & 10.0 & 2.45 & 97.98 \\
\hline
\end{tabular}

\section{Conclusion}

The developed technique using the HPLC-MS/ MS method allows detecting the heterocyclic aromatic amines in meat products at the concentrations (the limit of quantification of target substances) of as low as $3 \mathrm{ng} / \mathrm{g}$. Sample preparation by polar solvent extraction with diethyl ether may significantly reduce analysis time and cost relative to sample preparation method with SPE. In this connection, the method of sample preparation with liquid extraction may be recommended for routine tests, but for arbitration studies, the method of sample preparation with SPE is more preferable due to high analyte extraction degree. For the technique developed, the limit of detection and the limit of quantification of HAAs, the degree of their extraction for both methods of sample preparation, and indicators of accuracy and specificity were determined. The work performed allows to recommend the developed method for monitoring the accumulation of heterocyclic aromatic amines in meat products. 


\section{REFERENCES}

1. Zamora, R., Hidalgo, F.J. (2020). Formation of heterocyclic aromatic amines with the structure of aminoimidazoazarenes in food products. Food Chemistry, 313, Article 126128 https://doi. org/10.1016/j.foodchem.2019.126128

2. Utyanov, D.A., Kulikovskii, A.V., Vostrikova, N.L., Kuznetsova, 0.A. (2019). Products of chemical reactions that occur during high-temperature heat treatment of the meat products. Theory and practice of meat processing, 4(4), 17-22. https://doi. org/10.21323/2414-438X-2019-4-4-17-22

3. Meurillon, M., Erwan, E. (2016). Mitigation strategies to reduce the impact of heterocyclic aromatic amines in proteinaceous foods. Trends in Food Science \& Technology, 50, 70-84. https://doi.org/10.1016/j.tifs.2016.01.007

4. Dashwood, R. H. (2002). Modulation of heterocyclic amine-induced mutagenicity and carcinogenicity: An 'A-to-Z' guide to chemopreventive agents, promoters, and transgenic models. Mutation Research - Reviews in Mutation Research, 511(2), 89-112. https://doi.org/10.1016/S1383-5742(02)00005-4

5. Pezdirc, M., Žegura, B., Filipič, M. (2013). Genotoxicity and induction of DNA damage responsive genes by food-borne heterocyclic aromatic amines in human hepatoma HepG2 cells. Food and Chemical Toxicology, 59, 386-394. https://doi.org/10.1016/j. fct.2013.06.030

6. Takahashi, M., Furukawa, F., Miyakawa, Y., Sato, H., Hasegawa, R., Hayashi, Y. (1986). 3Amino-1-methyl-5H-pyrido[4,3-b] indole initiates two-stage carcinogenesis in mouse skin but is not a complete carcinogen. Japanese Journal of Cancer Research, 77(6), 509-513. https://doi.org/10.20772/cancersci1985.77.6_509

7. Schut, H. A. J., Snyderwine, E. G. (1999). DNA adducts of heterocyclic amine food mutagens: Implications for mutagenesis and carcinogenesis. Carcinogenesis, 20(3), 353-368. https://doi. org/10.1093/carcin/20.3.353

8. Butler, L. M., Sinha, R., Millikan, R. C., Martin, C. F., Newman, B., Gammon, M. D. et al. (2003). Heterocyclic amines, meat intake, and association with colon cancer in a population-based study. American Journal of Epidemiology, 157(5), 434-445. https://doi.org/10.1093/aje/kwf221

9. Butler, L. M., Millikan, R. C., Sinha, R., Keku, T. O., Winkel, S., Harlan, B. et al. (2008). Modification by $\mathrm{N}$-acetyltransferase 1 genotype on the association between dietary heterocyclic amines and colon cancer in a multiethnic study. Mutation Research - Fundamental and Molecular Mechanisms of Mutagenesis, 638(1-2), 162-174. https://doi.org/10.1016/j.mrfmmm.2007.10.002

10. Feldblyum, I.V., Alyeva, M. Kh., Markovich, N.I. (2016). The association between diet and the probability of colorectal cancer among the population of Perm krai: epidemiological study. Problems of nutrition, 85, 60-67. (In Russian)

11. Wang, B., Li, H., Huang, Zh., Kong, B., Liu, Q., Wang, H. et al. (2021) Dynamic changes in the qualities and heterocyclic aromatic amines of roasted pork induced by frying temperature and time. Meat Science, 176, Article 108457. https://doi. org/10.1016/j.meatsci.2021.108457

12. Alaejos, M.S., Afonso, A.M. (2011). Factors that affect the content of heterocyclic aromatic amines in foods. Comprehensive Reviews Food Science and Food Safety, 10(2), 52-108. https://doi.org/10.1111/j.1541-4337.2010.00141.x

13. Hasnol, N.D.S., Jinap, S., Sanny, M. (2014). Effect of different types of sugars in a marinating formulation on the formation of heterocyclic amines in grilled chicken. Food Chemistry, 145, 514-521. https://doi.org/10.1016/j.foodchem.2013.08.086 14. Gibis, M., Weiss, J. (2012). Antioxidant capacity and inhibitory effect of grape seed and rosemary extract in marinades on the formation of heterocyclic amines in fried beef patties. Chemistry, 134(2), 766-774. https://doi.org/10.1016/j.foodchem.2012.02.179
15. Keşkekoğlu, H., Üren, A. (2014). Inhibitory effects of pomegranate seed extract on the formation of heterocyclic aromatic amines in beef and chicken meatballs after cooking by four different methods. Meat Science, 96(4), 1446-1451. https://doi. org/10.1016/j.meatsci.2013.12.004

16. Tengilimoglu-Metin, M., Hamzalioglu, A., Gokmen, V., Kizil, M. (2017). Inhibitory effect of hawthorn extract on heterocyclic aromatic amine formation in beef and chicken breast meat. Food Research International, 99, 586-595. https://doi.org/10.1016/j. foodres.2017.06.044

17. Tengilimoglu-Metin, Kizil, M. (2017). Reducing effect of artichoke extract on heterocyclic aromatic amine formation in beef and chicken breast meat. Meat Science, 134, 68-75. https://doi. org/10.1016/j.meatsci.2017.07.018

18. Persson, E., Oroszvári, B.K., Tornberg, E., Sjöholm, I., Sk$\mathrm{og}$, K. (2008). Heterocyclic amine formation during frying of frozen beefburgers. International Journal of Food Science \& Technology, 43(1), 62-68. https://doi.org/10.1111/j.13652621.2006.01390.x

19. Gunter, F. L., Kuhnle, K., Chen, O. (2017). Vegetable oil as fat replacer inhibits formation of heterocyclic amines and polycyclic aromatic hydrocarbons in reduced fat pork patties. Food Control, 81, 113-125 https://doi.org/10.1016/j.foodcont.2017.05.043

20. Oz, E. (2021). The presence of polycyclic aromatic hydrocarbons and heterocyclic aromatic amines in barbecued meatballs formulated with different animal fats. Food Chemistry, 352, Article 129378. https://doi.org/10.1016/j.foodchem.2021.129378

21. Sun, F., Tan, H., Li, Y., De Boevre, M., Zhang, H., Zhou, J. et al. (2021). An integrated data-dependent and data-independent acquisition method for hazardous compounds screening in foods using a single UHPLC-Q-orbitrap run. Journal of Hazardous Materials, 401, Article 123266. https://doi.org/10.1016/j. jhazmat.202 0.123266

22. Dong, H., Xian, Y., Li, H., Wu, Y., Bai, W., Zeng, X. (2020). Analysis of heterocyclic aromatic amine profiles in Chinese traditional bacon and sausage based on ultrahigh-performance liquid chromatography-quadrupole-orbitrap high-resolution mass spectrometry (UHPLC-Q-orbitrap-HRMS). Food Chemistry, 310, Article 125937. https://doi.org/10.1016/j.foodchem.2019.125937

23. Shan, S., Ma, Yu., Sun, Ch., Guo, X., Zheng, H., Xu, X. et al. (2021). A novel magnetic solid-phase extraction method for detection of 14 heterocyclic aromatic amines by UPLC-MS/MS in meat products. Food Chemistry, 337, Article 12763. https://doi. org/10.1016/j.foodchem.2020.127630

24. Wu, Yu., Chen, L., Xian, Ya., Hou, X., Liang, M., Dong, H. et al. (2019). Quantitative analysis of fourteen heterocyclic aromatic amines in bakery products by a modified QuEChERS method coupled to ultra-high performance liquid chromatography-tandem mass spectrometry (UHPLC-MS/MS). Food Chemistry, 298, Article 125048. https://doi.org/10.1016/j.foodchem.2019.125048

25. Yan, Y., Zhang, S., Tao, G. -J., You, F. -H., Chen, J., Zeng, M. -M. (2017). Acetonitrile extraction coupled with UHPLC-MS/MS for the accurate quantification of 17 heterocyclic aromatic amines in meat products. Journal of Chromatography B: Analytical Technologies in the Biomedical and Life Sciences, 1068-1069, 173-179. https://doi.org/10.1016/j.jchromb.2017.10.015

26. Khan, M. R., Naushad, M., Alothman, Z. A., Alsohaimi, I. H., Algamdi, M. S. (2015). Solid phase extraction and ultra-performance liquid chromatography-tandem mass spectrometric identification of carcinogenic/mutagenic heterocyclic amines in cooked camel meat. RSC Advances, 5(4), 2479-2485. https://doi. org/10.1039/c4ra13967d 


\section{AUTHOR INFORMATION}

Dmitry A. Utyanov - candidate of technical sciences, research scientist, Laboratory of scientifically-methodical works and control-analytical researches, V. M. Gorbatov Federal Research Center for Food Systems of Russian Academy of Sciences. 26, Talalikhina, 109316, Moscow, Russia. Tel.: +7-495-676-79-61, E-mail: d.utyanov@fncps.ru

* corresponding author

Andrey V. Kulikovskii - candidate of technical sciences, a head chromatography laboratory, leading research scientist, Laboratory «Scientific and methodical work, biological and analytical research», V. M. Gorbatov Federal Research Center for Food Systems of Russian Academy of Sciences. 26, Talalikhina, 109316, Moscow, Russia. Tel.: +-495-676-60-11, E-mail: a.kulikovskii@fncps.ru https://orcid.org/0000-0002-9140-5390

Aleksandra S. Knyazeva - junior researcher, Laboratory “Scientific and methodical work, biological and analytical research", V. M. Gorbatov Federal Research Center for Food Systems of Russian Academy of Sciences. 26, Talalikhina, 109316, Moscow, Russia. Tel.: +7-495-676-79-61, E-mail: a.knyazeva@fncps.ru https://orcid.org/0000-0002-0038-9744

Anastasiya A. Kurzova - junior researcher, Laboratory "Scientific and methodical work, biological and analytical research", V. M. Gorbatov Federal Research Center for Food Systems of Russian Academy of Sciences. 26, Talalikhina, 109316, Moscow, Russia. Tel.: +7-495-676-79-61, E-mail: a.kurzova@fncps.ru https://orcid.org/0000-0001-5679-3984

Andrew N. Ivankin - doctor of chemical sciences, professor, Head of the Department of Chemistry, Mytischi Branch (MB) of Bauman Moscow State Technical University (National Research University). 1, 1st Institutskayay, 141005, Mytischi, Moscow region, Russia. Tel.: +7-498-687-36-00. E-mail: aivankin@inbox.ru https://orcid.org/0000-0002-6557-2697

All authors bear responsibility for the work and presented data.

All authors made an equal contribution to the work.

The authors were equally involved in writing the manuscript and bear the equal responsibility for plagiarism.

The authors declare no conflict of interest. 